\title{
THE MANAGEMENT OF PATIENTS PRESENTED WITH BLACK STONE POISONING: AN EXPERIENCE OF A TERTIARY CARE HOSPITAL
}

\author{
Mehwish Haqdad, Sameer Qureshi, Anam Ahmed \\ Jinnah Post Graduate Medical Center, Karachi Pakistan
}

\begin{abstract}
Objective: Management of patients who presented with blackstone poisoning/Paraphenylenediamine (PPD). Study Design: Observational descriptive study.

Place and Duration of Study: ENT Head and Neck Surgery Department, Jinnah Post Graduate Medical Center (JPMC) Karachi, from Jan 2019 to Dec 2020.

Methodology: Proforma was designed to collect data for the study. Patients and/or attendants were asked questions regarding PPD ingestion reason, evidence of poison ingestion, symptoms, color, and route and time interval to reach hospital. All of the collected were entered in SPSS and analyzed using SPSS version 21. Descriptive statistics in terms of mean \pm standard deviation or frequencies with percentages were computed to summarize the collected data as appropriate.

Result: Total 44 patients came to emergency department with diagnosis of black stone (kalapathar poisoning) as evident by patient or by attendant. Out of them 29 patients were female (65.9\%). Majority of patients $35(79.54 \%)$ were age between $15-30$ years Most of the patients 41 (93.18\%) took more than 2 hours to reach hospital patients were of age between 41-50 years. Forty-two (95.5\%) out of 44 ingested PPD with an intention to suicide while only $2(4.5 \%)$ patients ingested PPD accidentally. Forty patients $(90 \%)$ had severe tongue and neck swelling and underwent emergency tracheostomy while on the other hand, only 4 patients $(9.09 \%)$ presented with minor tongue swelling and cervicofacial edema impending stridor clinically. Out of these 4 patients, 2 further underwent emergency tracheostomy.

Conclusion: Paraphenylenediamine poisoning is commonly used in Pakistan for suicidal purpose especially in females as its easily available and cheap. All of the patients need Emergency tracheostomy due to angioneurotic edema leads to asphyxia. Therefore, we need to spread awareness so that its availability should be banned and Psychiatrists should do counseling of such patients for their mental health.
\end{abstract}

Keywords: Paraphenylenediamine (PPD), Angioneurotic edema, Renal failure, kalapathar poisoning, cervicofacial edema, emergency tracheostomy, suicidal, Asphyxia , Rhabomyolysis, stridor,Antidote

How to Cite This Article: Haqdad M, Qureshi S, Ahmed A. THE Management of Patients Presented with Black Stone Poisoning: An Experience of a Tertiary Care Hospital. Pak Armed Forces Med J 2021; 71 (Suppl-3): S569-572. Doi: https://doi.org/10.51253/pafmj.v1i1.7942

This is an Open Access article distributed under the terms of the Creative Commons Attribution License (https://creativecommons.org/licenses/by-nc/4.0/), which permits unrestricted use, distribution, and reproduction in any medium, provided the original work is properly cited.

\section{INTRODUCTION}

A poisonous substance is a physical or chemical agent that causes adverse events when it is ingested by the human. ${ }^{1}$ The first ever toxicity of PPD was identified after occupational exposure by hair dresser in 1924. ${ }^{2}$ Paraphenylenediamine (PPD) is an odoriferous chemical compound which commonly recognized as 'Kala Pathar' (black stone). Apparently the stone is solid and white in color which turns to black color when being oxidized. ${ }^{3}$ In Middle East, India and African countries, it is commonly used for coloring of feet, hands and hair dying with mixture ofheena that gives a shade of dark red. ${ }^{4}$ Black stone is easily accessible in crystals form that is crushed and mixed with lawsonia leaves for dying hairs. ${ }^{5}$

Dysfunction of many organs is caused by ingestion of PPD. ${ }^{6}$ Toxicity of PPD mainly depends on its

Correspondence: Dr Mehwish Haqdad, ENT Head and Neck Surgery, Jinnah Post Graduate Medical Center, Karachi Pakistan dose. The dose which is harmful is likely to be $7-10 \mathrm{~g}$. Consequences of PPD intake are angioneurotic edema that causes cervico-facial swelling which furthers leads to asphyxia, rhabdomyolysis which leads to renal failure. ${ }^{7}$ Frequent manifestations include sinus, tachycardia, bradycardia, edema of neck, face, tongue, larynx and pharynx, toxic hepatitis and hemodynamic instability. 7,8 In early stages, ingestion of PPD is related with high mortality because of development of arrhythmia and asphyxia and rhabomyolysis followed by renal failure. $^{7}$

There is no specific test for establishing diagnosis and a high index of suspicion is required to diagnose based on clinical assessment, laboratory investigation and detailed history. ${ }^{9}$ As there is no specific antidote for it, until now the treatment is conservative management which includes excessive diuresis and tracheostomy for prevention of respiratory failure and obstructed airway respectively. ${ }^{10}$ Presentation of patients 
with neck swelling after ingestion of PPD is the sign for emergency tracheostomy as the patients airway will be obstructed if they will not undergo tracheostomy immediately. ${ }^{5}$ Early stomach pumping has also role in reducing mortality and dialysis is required for patients presenting with renal failure. ${ }^{7}$

Many studies have been done for emphasizing black stone poisoning as emerging trend for suicidal attempts. In Pakistan most of the cases are reported from South Punjab and Sindh. ${ }^{11}$ Clinical judgment has important role for timely management as conservative management is not preferred for such cases. Therefore, the purpose of the study is to investigate the reason of PDD poisoning and to highlight the manifestation factors, approach to treat patients based on clinical judgment and outcomes of the patients presented with PPD poisoning.

\section{METHODOLOGY}

This observational descriptive study was conducted at ENT Head and Neck Surgery Department, Jinnah Post Graduate Medical Center (JPMC) Karachi, from January 2019 to December 2020 after taking approval from Institutional Review Board.

Inclusion Criteria: Patients with black stone poisoning were included, Both gender were includes.

Exclusion Criteria: Patients who did not show any clinical sign or biochemical proof of poisoning and patients previously known for airway disease and allergy were excluded. Chest radiographs were done in emergency department to exclude lung pathology.

All patients who presented with black stone (kalapathar) poisoning at Emergency Department in JPMC. Detail examination was performed by attending doctor and treating consultant. After taking informed consent, patients were included in the study. Proforma was designed to collect data for the study. Patients and/or attendants were asked questions regarding PPD ingestion reason, evidence of poison ingestion, symptoms, color, and route and time interval to reach hospital.

Diagnosis was established for each patient on the basis of history of poison ingestion as provided by patient and/or attendant. Clinical features of the patients were documented at the time of presentation. Patients presented with tongue swelling or cervicofacial swellings with stridor and who were not maintaining oxygen saturation checked by pulse oximetry and monitors in Emergency Department. These patients were planned to undergo the procedure of emergency tracheostomy.
Patients presented with mild tongue and neck swelling, minor dose ingestion and short timer interval were given IV steroids stat shot and observed for neck swelling and oxygen saturation after providing oxygen support and maintaining IV lines. While the patients who had taken heavy dose of poison and presented to Emergency department with huge neck and tongue swelling and failed for endotracheal intubation were immediately shifted to emergency operation theatre with oxygen support and emergency tracheostomy was performed after taking informed consent.

All of the collected were analyzed using SPSS-21. Descriptive statistics in terms of mean \pm standard deviation or frequencies with percentages were computed to summarize the collected data as appropriate.

\section{RESULTS}

Total 44 patients came to emergency department with diagnosis of black stone (kalapathar poisoning) as evident by patient or by attendant. Out of them 29 patients were female $(65.9 \%) 35(79.54 \%)$ were age between 15-30 years. Most of the patients 41 (93.18\%) took more than 2 hours to reach hospital 42 (95.5\%) out of 44 ingested PPD with an intention to suicide.

All cases presented with tongue or cervicofacial swelling/edema. Forty patients $(90 \%)$ had severe tongue and neck swelling. These patients developed stridor clinically and couldn't maintain oxygen saturation and as a consequence underwent emergency tracheostomy after maintaining IV lines, giving oxygen supports through mask and administering IV steroids according to age and weight.

While on the other hand, only 4 patients $(9.09 \%)$ presented with minor tongue swelling and cervicofacial edema impending stridor clinically. Out of these 4 patients, 2 were arrived early in emergency department. They could maintain oxygen saturation with oxygen support so that they were kept for under strict observation provided that 10 litre oxygen support through mask, well maintained Iv line and Iv steroid stat shot. Out of these 4 patients 2 were shifted to emergency OR for emergency tracheostomy after observation due to development of stridor clinically while 2 were remained stable and shifted to National poisoning control programme in Jinnah post graduate medical center Karachi. These 2 were the patients who arrived early to emergency department and had taken minute dose as compare to other patients and their symptoms relieved by conservative management by means of IV steroids stat dose according to weight. All of the patients were shifted to National poisoning control program after 
performing the emergency tracheostomy and managing them in ER.

$\begin{aligned} & \text { Table: Demographic characteristics, clinical presentation } \\
& \text { and outcome of ppd poisoning }\end{aligned}$
\begin{tabular}{l|c}
\hline Study Variables & Mean \pm SD $/ \mathbf{n}(\%)$ \\
\hline Age (in years) & $27.2 \pm 10.23$ \\
\hline Gender & $15(34.9)$ \\
\hline Male & $29(65.9)$ \\
\hline Female & $2(4.5 \%)$ \\
\hline Ingestion of PPD & $44(95.5 \%)$ \\
\hline Accidentally & $3(6.8)$ \\
\hline Suicidal attempt & $41(93.2)$ \\
\hline Duration Between Onset and Reporting to ER \\
\hline Within 2 hours ( $\leq 2$ hours) & $6(13.6)$ \\
\hline More than 2 hours (>2 hours) & $16(16.4)$ \\
\hline Time of Arrival to ER & $22(50)$ \\
\hline 12:00 pm - 3:00 pm & $40(90.9)$ \\
\hline $4: 00$ pm - 7:00 pm & $4(9.1)$ \\
\hline $8: 00$ pm - 12:00 am & $44(100)$ \\
\hline Presenting Condition & $40(90)$ \\
\hline Stridor & $82.9 \pm 5.4$ \\
\hline Impending stridor & $42(95.5)$ \\
\hline Tongue and cervico-facial swelling & $2(4.5)$ \\
\hline Huge Tongue and neck swelling & \\
\hline SpO2 & \\
\hline Emergency Tracheostomy Performed & \\
\hline Yes & \\
\hline No & \\
\hline \multicolumn{2}{|l}{} \\
\hline
\end{tabular}

\section{DISCUSSION}

Chemically PPD is derived from coaltar which produces Bondrowski's base when oxidized that is toxic, allergic and mutagenic in nature and is easily available in markets at low cost which is the cause of its frequent ingestion in Asia and other developing countries for purpose self-harming intentionally. ${ }^{12}$ The similar trend is found in our study. Forty one patients out of 44 ingested PPD to deliberately harm their self. On the other hand, only patients were presented with accidentally ingestion of PPD. It has been also reported by Haider et al, ${ }^{10}$ and Tanweer et al, ${ }^{7}$ in their study that $100 \%$ and $82.8 \%$ deliberately ingested PPD to for selfharming respectively.

Most of the cases of hair dye poisoning are seen in young females with an intention to commit suicide, ${ }^{11}$ In our study, majority of the participants 29 (65.9\%) were females who deliberately ingested PPD. These females were under age of 30 years and most of them presented in evening and arrived to the hospital with delay which is evident behavior towards suicidal attempts. A study conducted in DI Khan, also showed that females are more victims of black stone poisoning than man. The reported male to female ratio in his study was 1:18.13 The reason of intentional use of PDD poisoning among females may be linked to dealing with social pressure and gender inequalities in developing countries.

It was found in our study that 35 (79.54\%) patients were age group of 15-30 years that is the mainly young age group people admitted that they ingested PPD for suicidal purpose. The finding of study is in agreement with WHO report which states that young age people are more exposed to self-harm in low middle and income countries. ${ }^{14}$ A study conducted in DI Khan, Pakistan in 2016 also reported the similar finding that $65.8 \%$ people were aged between $15-24$ years and overall $94.74 \%$ patients ingested PPD with suicidal intention. ${ }^{13}$

Commonly patients ingesting PPD poisoning present with arrhythmia, sinus, edema of neck, tongue, face, larynx or pharynx, asphyxia, rhabdomyolysis followed by renal failure. ${ }^{7}$ But in our study all of the patients showed only manifestation of tongue or cervicofacial swelling/edema out of which $40(90 \%)$ patients were with severe neck and tongue swelling and clinically developed stridor. While $4(10 \%)$ patients showed symptom of minor neck and tongue swelling. Patients presented with severe neck and tongue underwent emergency tracheostomy. The finding is consistent with the study conducted in Pakistan by Tanweer et al, ${ }^{7}$ in which $95 \%$ patients developed the symptom of cervicofacial edema and underwent emergency tracheostomy. Qadri et al,15 stated in his study the most frequent sign for emergency tracheostomy is PPD poisoning. All patients presented with severe angioneurotic edema underwent emergency tracheostomy in a study conducted by Sulaiman et al, ${ }^{16}$ Akram at el, 17 and Qasim et al, ${ }^{18}$ in their study reported that emergency tracheostomy was performed for all patients for prevention of dyspnea.

Time of arrival to hospital also plays a major role in saving the life of the patient. ${ }^{19}$ Majority of patients $41(93.18 \%)$ made delay in seeking treatment and took more than 2 hours to reach to hospital. The cause of delay may be stigma of suicide in a society. The similar finding reported by Tanweer et al,7 that median time to presenting in ER from ingestion was 6 hours.

Nearly all cases of PPD poisoning ingest it orally however percutaneous toxicity has also been observed. ${ }^{20}$ In our study all of the patients ingested PPD through oral route but exact quantity of ingested PPD was remain unknown in our study. 
The limitation of the present study is that patients were observed till they received treatment either in emergency department or underwent emergency tracheostomy after that all of the patients were shifted to National Poisoning Control Program at JPMC. Patients were not followed after they shifted to National Poisoning Control Program. Therefore other treatment modalities were not discussed here except airway management It is suggested that to study the outcomes of patients more appropriately other treatment modalities should be discuss and patient should follow up for a month at least until they discharge.

\section{ACKNOWLEDGEMENT}

We are thankful to our parents, teachers and friends.

\section{CONCLUSION}

PPD poisoning is commonly used in Pakistan for suicidal purpose especially in females as it's easily available and cheap. All of the patients need Emergency tracheostomy due to angioneurotic edema leads to asphyxia. Therefore, we need to spread awareness so that its availability should be banned and Psychiatrists should do counseling of such patients for their mental health.

\section{Conflict of Interest: None.}

\section{Authors' Contribution}

$\mathrm{MH}$ : Conception framework, drafting and analysis, SQ: Critical review, AA: Data collection.

\section{REFERENCES}

1. Elgamel AA, Ahmed NO. Complications and management of hair dye poisoning in Khartoum. Sud Med Monit 2013; 8(3): 146148.

2. Narang U, Jain V, Jain AP. Hair dye: An emerging suicidal agent. J Mah Gand Inst Med Sci 2015; 20(1): 52-55.

3. Khaskheli MS, Shaikh S, Meraj M, Raza H, Aslam I. Paraphenylenediamine poisoning: clinical features, complications and outcome in a tertiary care institute. Anaesthesia, Pain Inten Care 2019; 2(1): 343-347.

4. Punjani NS. Paraphenylene diamine (hair dye) poisoningleading to critical illness neuropathy. J Neurol Disord 2014; 2(180): 2-5.
5. Ishtiaq R, Shafiq S, Imran A, Masroor Ali Q, Khan R, Tariq H, et al. Frequency of acute hepatitis following acute paraphenylene diamine intoxication. Cureus 2017; 9(4): e1186.

6. Ishaque S, Jurair H, Siyal H, Kaala Pathar (paraphenylene diamine) poisoning and angioedema in a child: an unusual encounter. J Clin Toxicol 2016; 6(294): 1-5.

7. Tanweer S, Saeed M, Zaidi S, Aslam W. Clinical profile and outcome of paraphenylene diamine poisoning. J Coll Phys Surg Pak 2018; 28(5): 374-377.

8. Ram R, Swarnalatha G, Prasad N, Dakshinamurty KV. Paraphenylene diamine ingestion: an uncommon cause of acute renal failure. J Postg Med 2007; 53(3): 181-112.

9. Dorra A, Ines G, Nouioui A, Khlifi F, Salah D, Masri W, et al. Paraphenylenediamine Poisoning in Tunisia: A Case Report. Arab J Forens Sci Foren Med 2015; 230(1856): 1-5.

10. Haider SA, Sultan A, Salman Z, Waris S, Bandesha Y. Paraphenylenediamine poisoning: clinical presentations and outcomes. Anaesth Pain Inten Care 2018; 22(1): 43-48.

11. Umair SF, Amin I, Urrehman A. Hair Dye poisoning: An early intervention. Pak J Med Sci 2018; 34(1): 230-232.

12. Krishnaswamy $S$, Sooraj Y. Hair dye poisoning and the developing world. J Emerg 2009; 2(2): 129-131.

13. Khan H, Khan N, Khan N, Ahmad I, Shah F, Rahman AU, et al. Clinical presentation and outcome of patients with paraphenylenediamine (kala-pathar) poisoning. Gomal J Med Sci 2016; 14(1): $1-5$.

14. The Global Health Observatory. World Health Organization. [Internet] Available from https://www.who.int/data/ gho/ data/themes/topics/topic-details/GHO/world-health-statistics

15. Qadri SH, Haq I, Haq E. An audit of the emergency tracheostomies in a tertiary care hospital. JSZMC 2014; 5(2): 615-618.

16. Suliman S, Fadlalla M, Nasr M, Beliela M, Fesseha S. Poisoning with hair-dye containing paraphenylene diamine: ten years experience. Saudi J Kid Dis Transpl 1995; 6(3): 286-289.

17. Akram A, Shahid R, Tariq M. Kala pathar (paraphenylene diamine) poisoning; role of tracheostomy: our experience at DHQ hospitals. Pak J Med Health Sci 2018; 12(2): 865-866.

18. Qasim AP, Ali MA, Baig A, Moazzam MS. Emerging trend of self harm by using 'Kala Pathar' Hair Dye (paraphenylene diamine): an epidemiological study. APMC; 2016; 10(1): 1-5.

19. Mahsud I. Role of tracheostomy in reducing mortality from kala pathar (paraphenylene diamine) poisoning. Gomal J Med Sci 2015; 13(3): 1-5.

20. Kallel H, Chelly H, Dammak H, Bahloul M, Ksibi H, Hamida CB, et al. Clinical manifestations of systemic paraphenylene diamine intoxication. J Nephrol 2005; 18(3): 308-311. 